\title{
Processo de Fabricação Digital de Artefato para Transporte de Maças
}

Digital Process for Manufacturing Artifact for Apples Transport

> Carlo Rossano Manica

Universidade Federal do Rio Grande

do Sul, Brasil

crmanica@yahoo.com.br

\author{
> Leonardo Barili Brandi \\ Universidade Federal do Rio Grande \\ do Sul, Brasil \\ leonardo.barili@gmail.com
}

> Fabio Gonçalves Teixeira

Universidade Federal do Rio Grande do Sul, Brasil

fabiogt@ufrgs.br

> Osorio Schaeffer

Universidade Federal do Rio Grande do Sul, Brasil

osoriosch@gmail.com
> Renan Wiliam Leite Pereira

Universidade Federal do Rio

Grande do Sul, Brasil

renan.pereira@ufrgs.br

> Underléa Miotto Bruscato

Universidade Federal do Rio

Grande do Sul, Brasil

arqlea@gmail.com

\begin{abstract}
This article presents the result of the activities carried out for the discipline of the program Master in Design and Technology (UFRGS), Digital Manufacturing Process as a Tool for Project. It aimed to develop a product based on digital manufacturing process. With this purpose, was designed a package for the transport of apples. In order to achieve the goal the generation of alternatives was conducted through a game and Sketch Creative Brainstorming, followed by research on the product life cycle. Subsequently, was used parametric modeling software for the package design. The use of three-dimensional modeling software Rhinoceros together with the plug-in Grasshopper allowed the construction of three-dimensional parametric models. As a result, we obtained the creation of a product that can be adapted to other fruits, avoiding rework, and run through rapid prototyping, this being a consequence of the facilities of adoption of digital fabrication.
\end{abstract}

Keywords: Digital fabrication; Parametric modeling; grasshoper; Packaging, Apple.

\section{Introdução}

Tecnologias computacionais fazem parte da rotina na elaboração de projetos nas áreas da arquitetura, design e engenharia. A tecnologia CAD - Computer Aided Design, permite trabalhar informaçôes bidimensionais e tridimensionais. Com as tecnologias CAM Computer Aided Manufacturing, as informaçóes digitais geradas anteriormente podem ser interpretadas em máquinas de controle numérico computacional (CNC), que materializam os objetos do projeto virtual utilizando diferentes técnicas e materiais. Todo esse processo caracteriza a Fabricação Digital que se estrutura como uma cadeia integrada de processos desde a concepção até a produção.

Através das ferramentas de fabricação digital é possível acelerar o processo de desenvolvimento de produtos, pois se pode passar de modelos virtuais para modelos físicos rapidamente e sem grandes custos, facilitando o entendimento das possibilidades de modelos. Com isso, empresas pequenas e instituiçóes de ensino conseguem materializar produtos e protótipos, o que com as ferramentas de fabricação tradicionais, como rotomoldagem e injeçáo, não seria possível devido ao custo elevado. Impressoras 3D, cortadoras a laser e fresadoras são algumas das máquinas utilizadas no processo de fabricação digital. Essas ferramentas permitem realizar protótipos e pequenas séries de produtos, o que indica uma relação desse processo com a produção em pequena escala e a personalização de produtos (Eychenne e Neves, 2013).

O presente artigo apresenta o resultado de uma das atividades realizadas para a disciplina de Processos de Fabricação Digital como Ferramenta de Projeto oferecida pelo programa de Pós Graduação em Design da Universidade Federal do Rio Grande do Sul (Brasil), tendo como objetivo desenvolver um produto, introduzindo no processo de projeto da criação ao desenvolvimento, ferramentas digitais de representação, explorando as possibilidades de integração do desenho paramétrico à prática de novos processos de projeto, prototipagem rápida e fabricação digital, aplicadas à racionalização de sistemas construtivos em design, arquitetura e engenharia.

A premissa inicial foi a criação de um produto que resolvesse e integrasse todo o ciclo de produçáo. Neste sentido foi proposta a criação de um artefato para o transporte de frutas. O produto resultante deveria ser incorporado ao processo tradicional de transporte de maçãs, auxiliando desde a colheita até a chegada ao ponto de venda, e retornando para ser novamente utilizado junto às macieiras.

Com vistas a alcançar o objetivo, foram realizadas as seguintes etapas: geraçáo de alternativas através do jogo Creative Sketch, Brainstorming; pesquisa acerca do ciclo de vida do produto; modelagem paramétrica e prototipagem. O jogo Creative Sketch consistiu na aplicação de uma sequência de quatro técnicas criativas pensadas para gerar um grande número de ideias de projeto (Cardozo, 2012). À medida que o jogo evoluiu, foi se fazendo uma seleção das melhores ideias, culminado, ao final, na escolha da melhor ideia para um produto em potencial. No brainstorming deveriam ser produzidos cinco sketches, propondo cinco produtos. Após o brainstorming, foi aplicada a técnica chamada gatilho de ideias, na qual, a partir de uma palavra aleatória, foram geradas novas ideias de produtos. Esta técnica visa estimular o pensamento lateral, "a fim de ultrapassarmos as ideias mais óbvias” (Baxter, 1995, pg. 
65). Nesta fase, geraram-se quatro ideias de produtos. No segundo momento, aplicou-se o método de princípios inventivos (MPI) da TRIZ, sigla russa para Teoria da Solução Inventiva de Problemas. Diferente das técnicas anteriores, de características intuitivas, a TRIZ é um método sistemático para estimular a criatividade (Back, et al., 2008). A última técnica aplicada foi a dos 6 Chapéus, método criado pelo médico inglês Edward de Bono para explorar novas ideias e tomar decisóes. Este método busca organizar o pensamento criativo, gerando diferentes visóes sobre uma ideia/problema.

Após a geração de ideias, foi realizada a modelagem paramétrica, que mostrou ser uma boa opção para a obtençáo de alternativas em tempo real. Definiu-se uma média do volume da maçã e buscou-se a inspiração na biônica para adequação da célula de armazenamento das frutas, utilizando o formato de favo de mel como referência.

Ao contrário da modelagem CAD tradicional, a modelagem paramétrica permitiu testar diferentes configuraçôes sem recomeçar do início, pois se podem alterar rapidamente os parâmetros, variando as dimensóes, relaçóes e proporçóes entre os elementos do produto, obtendo assim diferentes resultados. A adoçáo do software de modelagem tridimensional Rhinoceros juntamente com o plug-in Grasshopper permitiu a construçáo de modelos paramétricos tridimensionais.

Através dessa simulação, foi possível testar cores, acabamentos, visualizar como as bandejas ficariam encaixadas/empilhadas, entre outros testes preliminares como a disposição das maçãs. Além disso, a modelagem trouxe flexibilidade de dimensionamento ao produto, que pode ser aplicável para a adaptação de frutas diferentes.

Antes da prototipagem, recomenda-se que seja realizado um modelo físico preliminar, para testes, verificaçóes e correçóes. Para sua elaboração, utilizaram-se as vistas geradas pelo software de modelagem digital e material alternativo à fabricação final (papelão), somente para verificar questóes básicas de estrutura, encaixe e volume. Estima-se que o produto possa ser prototipado através de impressora 3D (método aditivo) ou de usinagem (método subtrativo), tendendo o segundo processo a ser mais rápido - porém pode apresentar complicaçóes em função da espessura da bandeja e das concavidades, sendo necessário dividir o produto em várias peças.

Como resultado do processo de fabricação digital - embora parcial - obteve-se um produto que contempla os requisitos de projeto. Estima-se que ele seja útil em todo o ciclo de produção, distribuição e consumo de maçãs. $\mathrm{O}$ trabalho demonstrou o quanto o desenvolvimento de produtos está ligado às tecnologias digitais existentes, dada a adoção de softwares em quase todas as atividades do processo, com exceção da geraçáo de ideia inicial - quando foram realizados inúmeros desenhos à máo.

Como resultados, destaca-se que o produto criado pode ser adaptado a outras frutas, evitando retrabalhos, e ser executado através de prototipagem rápida, como consequência das facilidades de utilização da modelagem paramétrica.

\section{Desenvolvimento do produto}

O desenvolvimento do produto contou com as etapas de geração de ideias; delimitação do produto; pesquisas e análises (uso, funçóes e requisitos do produto); definição do desenho; fabricação digital.
Na etapa de geraçáo de ideias, foi desenvolvida uma dinâmica de jogo (Creative Sketch), que consistiu na aplicação de uma sequência de quatro técnicas criativas, pensadas para gerar grande número de ideias de projeto (Cardozo, 2012). À medida que o jogo evoluiu, foi se fazendo uma seleção das melhores ideias, culminado, ao final, na escolha da melhor ideia para um produto em potencial.

O briefing determinava a criação de um produto para o transporte de frutas que considerasse a diminuição de perdas e danos aos alimentos. A primeira técnica aplicada foi o brainstorming, quando deveriam ser produzidos cinco sketches, propondo cinco produtos. Após o brainstorming, foi aplicada a técnica chamada gatilho de ideias, na qual, a partir de uma palavra aleatória, foram geradas novas ideias de produtos. Esta técnica visa estimular o pensamento lateral, "a fim de ultrapassarmos as ideias mais óbvias" (Baxter, 1995, pg. 65). Nesta fase, geraram-se quatro ideias de produtos.

No segundo momento, aplicou-se o método de princípios inventivos (MPI) da TRIZ, sigla russa para Teoria da Soluçáo Inventiva de Problemas. Diferente das técnicas anteriores, de características intuitivas, a TRIZ é um método sistemático para estimular a criatividade (Back, et al., 2008).

A última técnica aplicada foi a dos 6 Chapéus, método criado pelo médico inglês Edward de Bono para explorar novas ideias e tomar decisóes. Este método busca organizar o pensamento criativo, gerando diferentes visóes sobre uma ideia/problema. Cada chapéu possui uma característica própria que reflete as diferentes percepçóes do projeto (De Bono, 1994). Por meio desta técnica, foi selecionada a ideia com maior potencial de desenvolvimento de cada grupo. No caso do projeto em questáo, a ideia selecionada e posteriormente desenvolvida foi um artefato para o transporte de frutas que contemplava todo o ciclo: desde o produtor, passando pelo beneficiamento e chegando até o ponto de venda.

Após a atividade do jogo, a equipe de projeto decidiu focar o produto para o transporte de um tipo específico de fruta, devido à grande variedade de tamanho e dureza/delicadeza das frutas. Decidiu-se trabalhar com o transporte de maçãs, por ser uma fruta com ampla produçáo no estado do Rio Grande do Sul, que tem grande volume de vendas e é comercializada durante o ano inteiro nos supermercados - graças ao armazenamento em câmara fria.

Tendo como ponto de partida a definição que a embalagem seria usada para o transporte de maçãs Fuji e Gala - por terem maior valor de mercado -, iniciou-se a coleta de dados que partiu de um brainstorming. Um dos principais resultados do brainstormig foi de que o produto deveria seguir todo o ciclo de uso da embalagem, ou seja, do produtor até o consumidor e daí retornar.

Com base nessas premissas, ficou definido que o produto deveria estar acondicionado em embalagem com medidas submúltiplas de $1,00 \mathrm{~m} \times 1,20 \mathrm{~m}$ (paletizável), de fácil empilhamento. Definiu-se que a capacidade máxima do empilhamento e do conteúdo limite em quilos da embalagem seria de $18 \mathrm{~kg}$.

Para a representação gráfica do produto, foram realizados esboços à mão e utilizados softwares de modelagem digital; contando com o plugin de parametrização Grasshopper. Nesta fase, foi realizado o refinamento das alternativas geradas durante o jogo, selecionando as que melhor cumpriam a lista de requisitos e ideias com potencial 
de adaptação, para retrabalhá-las através de esboços até a definição do desenho do produto (Figura 1).

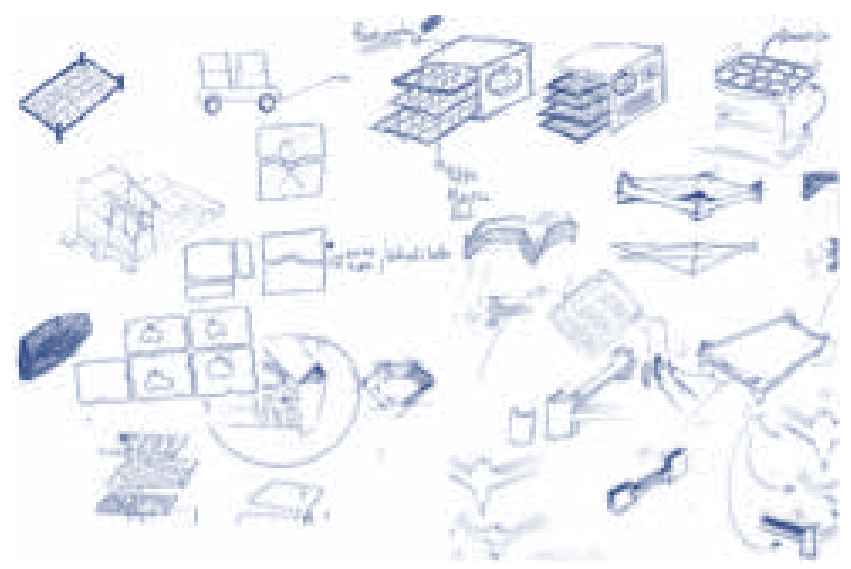

Figura 1: Esboços de refinamento de ideias, elaborado pelo autor.

\section{Fabricação Digital}

As atividades desenvolvidas a seguir, da ideia desenhada até o protótipo físico, caracterizam o processo de fabricação digital, que tem foco na criação e prototipagem rápida, quando é buscada a independência de produção em escala industrial.

As atividades de desenho bidimensional e projeção tridimensional foram as realizadas anteriormente, com a definição do desenho e projeção das vistas do produto. Este artigo, por ora, não contempla a atividade de prototipagem, contudo o restante do processo é descrito a seguir.

\section{Modelagem Digital Preliminar}

Para refinar o desenho; firmar dimensões, encaixes, volume e visualização prévia do produto, foi utilizado o software de modelagem digital Solidworks (Figura 2).

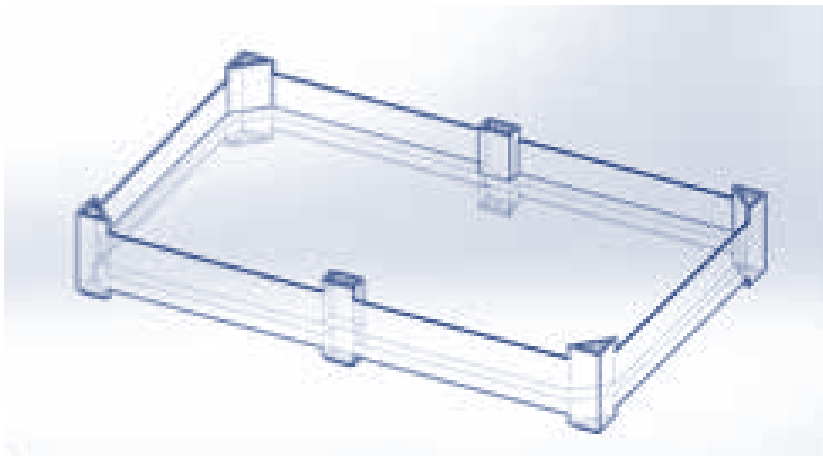

Figura 2: Definiçấo do desenho via modelagem digital, elaborado pelo autor.

Posteriormente, foram adotadas ferramentas computacionais e a parametrizaçáo para desenvolver o produto apresentado na imagem da Figura 2, agilizando assim as fases de projeto. Deste modo, usou-se o Rhinoceros juntamente com o Grasshopper, justamente pela sua facilidade de utilização e a sua maleabilidade de modelagem computacional.
Após realizado o estudo de volumetria e encaixes do artefato, foi definida a média do volume da maçã. Buscou-se inspiraçẫo na biônica para adequação da célula de armazenamento das frutas, utilizando o formato de favo de mel como referência (Figura 3).

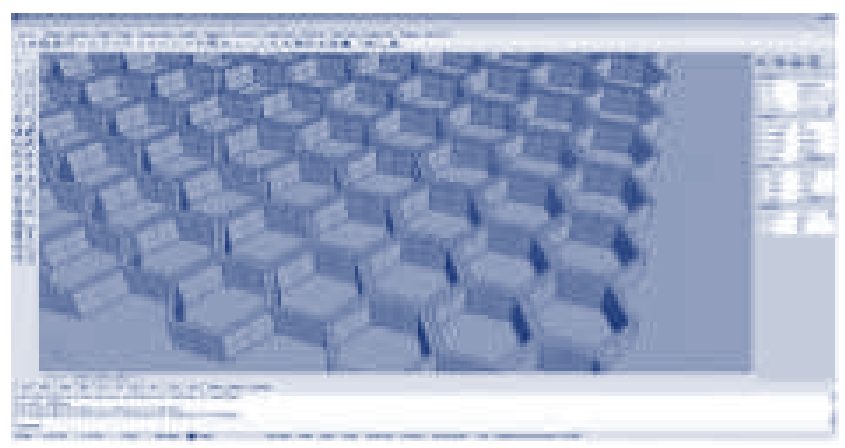

Figura 3: Desenvolvimento do artefato: ambiente virtual Rhinoceros, elaborado pelo autor

Após a modelagem parametrizada, utilizando o Grasshopper (Figura 4), adotou-se o software de modelagem digital NX Unigraphics quando foram realizados o arredondamento das arestas; o refinamento dos encaixes; o alivio de massa; o dimensionamento da espessura do artefato (Figura 5).

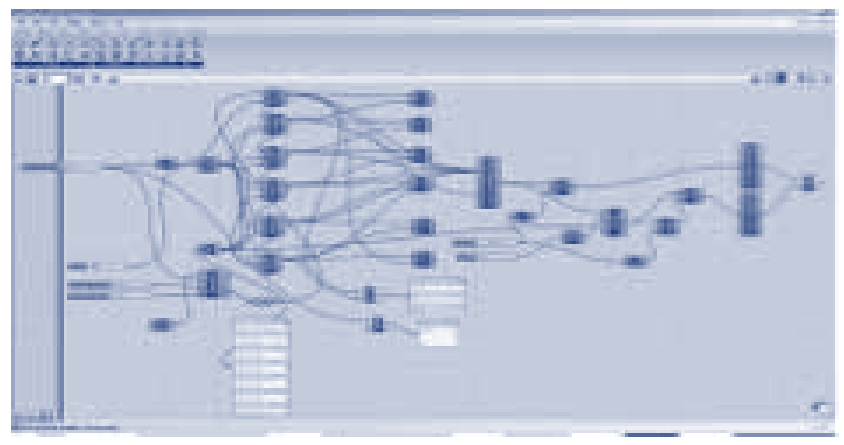

Figura 4: Desenvolvimento do artefato: ambiente virtual Grasshopper, elaborado pelo autor.

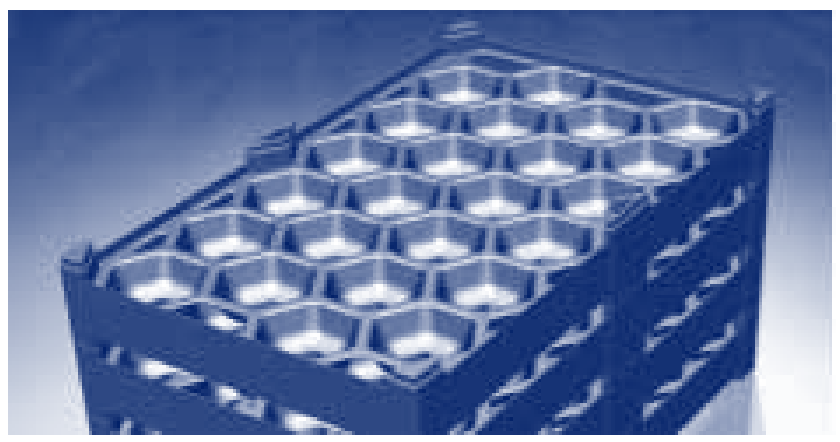

Figura 5: Desenvolvimento do artefato: ambiente NX Unigraphics, elaborado pelo autor.

Para melhor visualização do produto, foram realizadas simulaçóes visuais através de software de renderização Keyshot 3.0. 
Não foram realizadas simulaçóes da estrutura, somente simulaçóes estético/funcionais. Através dessa simulação, foi possível testar cores e acabamentos, além de visualizar como as bandejas ficariam encaixadas/empilhadas, entre outros testes preliminares como a disposição das maçãs (Figura 6).

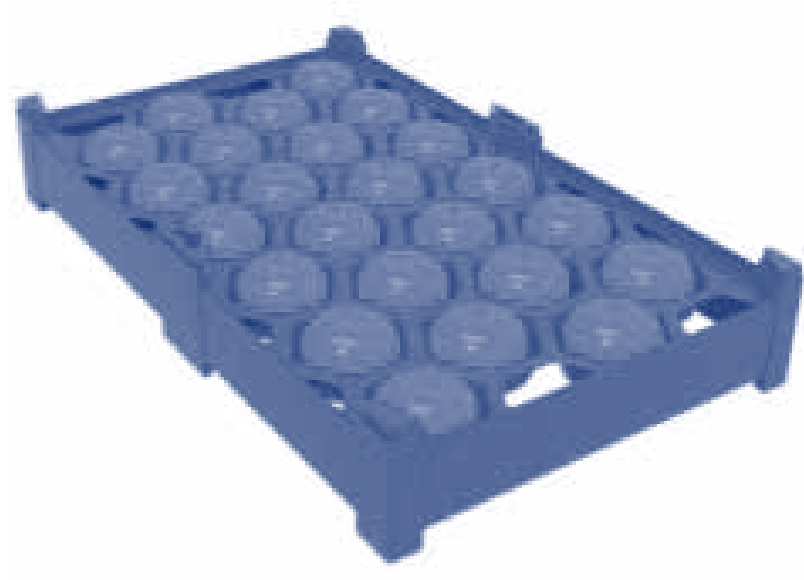

Figura 6: Simulação de uso: maçâs dimensionadas conforme padrão médio, elaborado pelo autor.

Antes da prototipagem, recomenda-se que seja realizado um modelo físico preliminar, para testes, verificaçóes e correçóes. Para sua elaboração, utilizaram-se as vistas geradas pelo software de modelagem digital e material alternativo à fabricação final (papelão), somente para verificar questóes básicas de estrutura, encaixe e volume.

Para a prototipagem, o produto deve ser ajustado ao sistema de produção (separaçáo em layers; reposicionamento de eixos, ajuste ao material de prototipagem, por exemplo) bem como os dados gerados pelo software devem estar compatíveis, em suas extensóes, com o equipamento selecionado. Devem ser verificadas e corrigidas superfícies que o equipamento é incapaz de elaborar ou que apresentarem falhas ao serem reproduzi, se necessitará de material de suporte e de material adequado para prototipagem.

Estima-se que o produto possa ser prototipado através de impressora 3D (método aditivo) ou usinagem (método subtrativo). $\mathrm{O}$ segundo processo tende a ser mais rápido, porém pode apresentar complicações em função da espessura da bandeja e das concavidades, sendo necessário dividir o produto em várias peças.

\section{Resultados}

Como resultado do processo de fabricaçáo digital - embora parcial obteve-se um produto que contempla os requisitos de projeto. Estima-se que ele seja útil em todo o ciclo de produção, distribuição e consumo de maçãs, tal como realizado na região.

Referente ao processo, destacam-se: os esboços de definiçáo do desenho, os quais materializaram o produto antes de iniciar a modelagem paramétrica; a modelagem digital preliminar, para facilitar a estruturação da rede de conexóes da modelagem paramétrica no Grasshopper; a modelagem paramétrica como fonte de criação e disposição de elementos, de modo que foi possível visualizar determinadas opçôes em um número imenso de alternativas para a disposiçáo das frutas na embalagem, otimizando o espaço e propiciando a criação de um produto ajustável.

\section{Conclusão}

O trabalho demonstrou o quanto o desenvolvimento de produtos está ligado às tecnologias digitais existentes, dada a utilização de softwares em quase todas as atividades do processo, com exceção da geraçáo de ideia inicial - quando foram realizados desenhos à mão.

O processo de fabricação digital exigiu ainda, neste caso, uma série de verificaçóes e medidas preliminares, para que não houvesse tantas falhas na atividade seguinte. É necessário que cada atividade gere uma saída bem definida, caso contrário, perde-se tempo no retrabalho das informaçóes ou a atividade seguinte pode ficar comprometida. Acredita-se que, à medida que houver evolução no domínio dos softwares, o processo se tornará mais fluído, rápido e eficaz.

Quanto à modelagem paramétrica, mostraram-se incontáveis possibilidades na forma do produto, tornando-se uma boa opção para geração de alternativas em tempo real. Ela também traz flexibilidade de dimensionamento ao produto, aplicável em família de produtos, por exemplo, para a adaptação a diferentes frutas.

\section{Referências}

Back, N. et all (2008). Projeto Integrado de Produtos: planejamento, concepção e modelagem. Barueri, SP: Manole Ltda.

Baxter, M (2000). Projeto de Produto: guia prático para o design de novos produtos. 2. Ed. São Paulo, SP: Edgar Blücher.

Bruscato, U. (2011). Práticas digitais na arquitetura: Seis experiências internacionais. Arquiteturarevista (UNISINOS), v. 7, p. 182-189, Editora Unisinos, São Leopoldo, RS.

Cardozo, G.A. (2012). Proposta de Jogo para a Solução de Problemas Não Estruturados com a Utilização de Técnicas Criativas. Dissertação (Mestrado em Design) - Programa de Pós-Graduação em Design, Universidade Federal do Rio Grande do Sul, Porto Alegre.

De Bono, E. (1994). Criatividade Levada a Sério. São Paulo, SP: Pioneira. Eychenne, F. \& Neves, H (2013). Fab Lab: A Vanguarda da Nova Revolução Industrial. São Paulo, SP: Editorial Fab Lab Brasil.

Martins, C. R. \& Farias, R. M (2002). Produção de Alimentos X Desperdício: Tipos, Causas e Como Reduzir Perdas na Produção Agrícola - Revisão. Revista da FZVA Uruguaiana, 9(1), 20-32.

Davidson, S. Grasshopper Algorithmic Modeling for Rhino. Disponível em <http://www.grasshopper3d.com/>

Mcneel, R. \& ASSOCIATES (2002). Rhinoceros NURBS modeling for Windows. Seattle. 